\title{
SATISFACTION FACTORS FROM THE WORK OF MEDICAL PROFESSIONALS, WORKING IN EMERGENCY MEDICAL CARE IN THE REPUBLIC OF BULGARIA
}

\author{
D. Todorova* \\ Faculty of Medicine, Trakia University, Stara Zagora, Bulgaria
}

\begin{abstract}
To study more comprehensively, analyze and summarize the satisfaction factors of the professional activity of the medical teams from CEMC. Preliminary interviews were conducted with medical professionals working at CEMC. On this basis, a questionnaire was developed, surveying through a sociological method the opinion of medical professionals from the Centers for Emergency Medical Care. Medical professionals, providing emergency medical care, face a number of challenges, which in turn have a direct impact on job satisfaction. We studied the satisfaction factors influencing the professional activity of the medical professionals working in the emergency medical care centers and their manifestations. The degree of professional satisfaction and its manifestations can be conditionally classified into 4 levels - high, medium, low satisfaction and complete dissatisfaction. The satisfaction factors and the level of overall satisfaction of the medical professionals working in the emergency medical care in the Republic of Bulgaria represent a number of complicated regularities, derived on a scientific basis. For the satisfaction of the emergency medical care professionals, it is necessary to provide factors that prevent dissatisfaction with the work and the organization of work, while, at the same time ensure conditions for the normal course of the activity, professional achievements and development.
\end{abstract}

Key words: Center for Emergency Medical Care, sustainability, policy, challenges.

\section{INTRODUCTION}

The satisfaction factors and the level of overall satisfaction of the medical professionals working in the emergency medical care in the Republic of Bulgaria represent a number of complicated regularities, derived on a scientific basis.

One of the theories of work motivation, successfully applied worldwide, is the twofactor theory of Frederick Herzberg. Based on his research in various work situations, he concludes that there are two main factors on which work motivation depends: Hygiene factors and Motivators.

The Hygiene factor affects the feeling of dissatisfaction that includes salary,

\footnotetext{
*Correspondence to: DEYANA GENCHEVA

TODOROVA, Faculty of Medicine, Trakia

University, Stara Zagora Armeyska Str. 11;

Bulgaria; mob. tel.: +359 8880095 40; e-mail:

deyanatodorova@abv.bg
}

occupational safety, interpersonal relationships, working conditions and others.

According to Abraham Maslow, if all opportunities to meet the physiological needs of the worker are provided, he or she will work better in return.

Herzberg's opinion, however, varied. He believed that the worker started paying more attention to the hygiene factors that satisfy physiological needs only after realizing that they were inadequate and unfair.

Work dissatisfaction occurs in organizations that have a weak staff policy, weak leadership, low pay and poor interpersonal relationships with management.

Dissatisfaction is absent in organizations that maintain different from the above conditions, namely: good staff policy, strong leadership, good pay and good interpersonal relationships with management. 
The Motivator that affects job satisfaction includes attractive work, opportunities for achievements, professional growth as well as responsibility assignments.

The motivator leads to long-term positive changes in the behavior of employees. The lack of conditions for its manifestation does not lead to a feeling of dissatisfaction, but its presence causes a feeling of satisfaction [16].

\section{MATERIALS AND METHODS}

The following materials and methods were used for the solution of the set tasks:

1. Analysis of documents

Available literature sources, officially published normative acts related to the legal regulation of emergency medical care until 2020 are analyzed.

Annual reports on the activity of the Center for Emergency Medical Aid (CSMP) and the Branch for Emergency Medical Aid (FSMP) in the country are also analyzed.

2. Analysis of media materials - print media, internet, television, radio, etc.

The realization of the tasks, the summary and the analysis of the obtained results was carried out by applying the following methods: historical, monographic, analysis and synthesis, method of comparison, induction and deduction, method of expert evaluation and empirical sociological research.

3. Sociological methods

A survey was conducted through interviews and three direct anonymous surveys related to the structure and organization of work, motivation for work, problems of emergency medical professionals, the introduction of telemedicine and patients in 2019 and 2020 with 325, 50 medical professionals and 200 patients. A personal expert assessment was made by the heads of CSMP and FSMP.

The study was conducted in CSMP and FSMP from different regions of the country with different structure and organization of work, which will allow us to analyze the work and problems of medical professionals providing emergency care in general.

4. Statistical methods

4.1. Descriptive statistics

One-dimensional frequency tables for category variables by calculating:

- absolute frequency - number of valid answers for each category of the variable;

- relative frequency -the percentage of valid answers for each category of the variable from the total number;
- percentage of valid answers - percentage of valid answers for each category of the variable from the number of valid answers;

- cumulative percentage - cumulative percentage of all categories of the variable.

4.2. Two-dimensional frequency tables for the category variables (Cross tables $2 \times 2$ and $n \times n-$ depending on the categories of the variables) with calculation of number and percentage of the total number.

5. Graphic analysis:

- pie and bar charts of the distribution for the category variables.

6. Statistical methods for dependencies:

6.1. Test of statistical hypotheses for dependencies between two category variables:

- coefficient $\chi^{2}$ (Pearson's method) - used for $2 \times 2$ Cross Table, when the expected frequencies in each cell of the table is $>5$;

- Fisher's exact method - used in $2 \times 2$ Cross Table, when the expected frequencies in some cells of the table is $<5$;

- linear coefficient $\chi^{2}$ - used at nxn Crosstable, when the expected frequencies in each cell of the table are> 5;

- coefficient $\chi 2$ (Kruskal-Wallis method) - used for $\mathrm{nxn}$ Cross-table, when the expected frequencies in some cells of the table are $<5$.

6.2. A statistically significant result is considered to be the significance level of the null hypothesis $\mathrm{p}<0.05$.

Statistical processing of empirical data was performed using a package for statistical analysis - statistical program SPSS 20 designed for research in the social sciences and Microsoft Office Excel 2016.

\section{RESULTS AND DISCUSSION}

We studied the satisfaction factors influencing the professional activity of medical professionals working in emergency care and their manifestations. The degree of professional satisfaction and its manifestations can be conditionally classified into 4 levels high, medium, low satisfaction and complete dissatisfaction.

A number of factors are involved in the complex satisfaction assessment:

The first satisfaction factor is the content and organization of work. The generalized opinion of the satisfaction with the content and the organization of the work is in the range from average $50.2 \%$ up to high satisfaction in $66.4 \%$ of the cases. The analysis of the data on this factor shows that the magnitude of manifestation in a total of the degrees of low 
satisfaction and complete dissatisfaction, although variable for the different criteria, has very low values - from $0.9 \%$ on the criterion volume of work performed to $6 \%$ on the criterion organization of work. The high satisfaction with the various criteria on the factor varies from $39.6 \%$ for the organization of work up to $66.4 \%$ on the criterion volume of work performed. It should be noted that, as a relative share, the degree of complete dissatisfaction does not exceed the high degree of manifestation in any of the criteria and, for some of the criteria, it is several times lower.

Table 1. Factors of professional satisfaction

\begin{tabular}{|c|c|c|c|c|}
\hline \multirow{3}{*}{ Factors } & \multicolumn{4}{|c|}{ Degree of professional satisfaction } \\
\hline & High & Medium & Low & $\begin{array}{c}\text { Complete } \\
\text { Dissatisfaction }\end{array}$ \\
\hline & $\%$ & $\%$ & $\%$ & $\%$ \\
\hline \multicolumn{5}{|l|}{ I. Content and organization of work: } \\
\hline 1. Dynamics of the working environment & 45,5 & 50,2 & 3,0 & 1,3 \\
\hline 2. Professional competence & 46,4 & 49,8 & 0,9 & 0,4 \\
\hline 3. Organization of work & 39,6 & 46,8 & 6,0 & 3,8 \\
\hline 4. Compaction of working hours & 59,6 & 33,6 & 2,6 & 0 \\
\hline 5. Volume of work performed & 66,4 & 28,1 & 1,7 & 0,9 \\
\hline \multicolumn{5}{|l|}{ II. Working conditions and remuneration: } \\
\hline 1. Professional equipment & 23,0 & 48,9 & 20,4 & 3,4 \\
\hline 2. Sanitary and hygienic conditions & 26,8 & 53,2 & 9,8 & 8,5 \\
\hline 3. Social and household needs & 19,6 & 54,9 & 12,3 & 9,4 \\
\hline 4. Amount of wages & 11,1 & 39,1 & 35,7 & 13,2 \\
\hline \multicolumn{5}{|l|}{ III. Mode of work and rest: } \\
\hline 1. Number of non-working days per year & 36,6 & 48,5 & 11,5 & 2,1 \\
\hline 2. Duration of duty & 54,0 & 39,6 & 3,4 & 1,7 \\
\hline $\begin{array}{l}\text { 3. Duration of the regulated time for rest during } \\
\text { work }\end{array}$ & 28,1 & 48,5 & 8,1 & 3,0 \\
\hline \multicolumn{5}{|l|}{ IV. Professional-business relations: } \\
\hline 1. With colleagues & 56,6 & 37,9 & 3,4 & 1,7 \\
\hline 2. With patients & 35,3 & 45,1 & 14,9 & 3,8 \\
\hline 3. With patients' relatives & 29,4 & 47,7 & 17,9 & 4,7 \\
\hline $\begin{array}{l}\text { V. Satisfaction with professional activity in } \\
\text { general }\end{array}$ & 23,0 & 68,5 & 7,2 & 0,4 \\
\hline
\end{tabular}

The deficits that demotivate a medical professional to build a high level of professionalism and to continue to persist in his or her work, despite the problems, are numerous. The problems are various with many of them being insurmountable as they have become part of the routine.

The majority of medical professionals work in conditions of constant compromises, lack of equipment, consumables, household destitution, staff shortages, etc.

The second satisfaction factor is working conditions and remuneration. It should be noted that according to the criteria of this factor - professional equipment, sanitary and hygienic conditions, social needs and the amount of wages, the high manifestation degree for none of these criteria reaches $50 \%$ of the overall number of surveyed medical professionals. The total range of manifestation is from $9.8 \%$ for the criterion sanitary and hygienic conditions to $35.7 \%$ for the criterion amount of work remuneration. When assessing the working conditions and the amount of remuneration from professional activity, it is seen that the largest group is from $3.4 \%$ to $13.2 \%$, indicating complete dissatisfaction with these factors. It follows that for the majority of medical professionals the factor of working conditions and the amount of remuneration is 
not a factor, satisfying their professional activity.

The majority of the medical professionals barely cover their costs with a lot of work and dissatisfaction with the conditions in which they work. The inertia of the hopeless professional existence and the lack of alternatives drag them along with the last remnants of a youthful dream to dedicate themselves to the most humane profession, with all their heart and mind, with the only condition - the respect of society that accompanied this profession in the past.

Reforming the system means harmonizing the salaries and controlling the imbalance of the remunerations for the different types of specialized medicine.

The third important factor is the mode (regime) of work and rest. Satisfaction with the work and rest mode is related to the non-working days within the year, the duration of the duty, as well as the regulated time for rest during work. Among the criteria for this factor, the criterion duration of duty meets the high satisfaction level for $54 \%$ of the medical professionals. For all other criteria, total satisfaction is below $50 \%$.

Here again, the limit of the values is average. Our conclusion is that, in general, for the majority of medical professionals the mode of work and rest does not act as a factor, satisfying their professional activity.

The results we received from the survey for actually used days off (non-working days) by the medical professionals show that $0.4 \%$ of them can afford up to 10 days of leave, $9.8 \%$ up to 20 days, $21.3 \%$ up to 30 days, $63.4 \%$ more than 30 days, and $0.9 \%$ of respondents cannot afford annual leave.

The fourth main factor is professional-business relationships. Professional business relationships with colleagues bring high satisfaction to medical professionals in $56.6 \%$ of cases, while the relationships with patients predetermine average satisfaction in $45.1 \%$ of cases.

The fifth factor is satisfaction from the professional activity as a whole.

Data on the fifth factor are visualized in Figure 1.

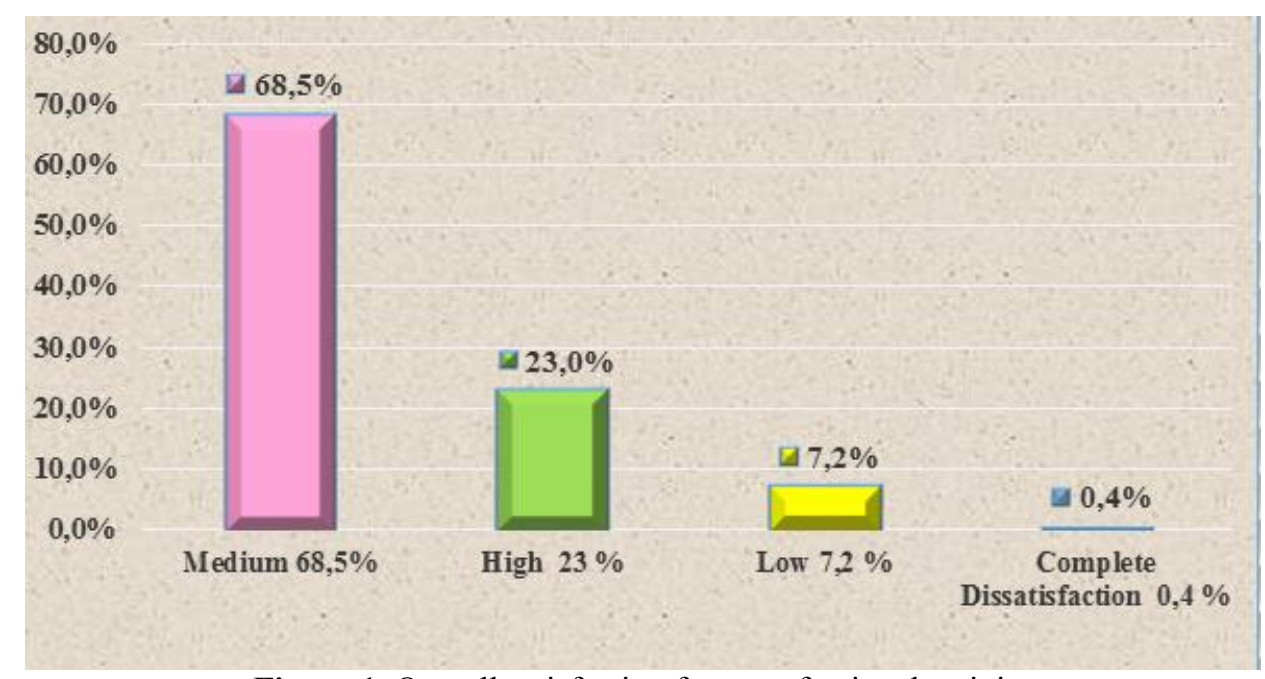

Figure 1. Overall satisfaction from professional activity

More than half - $68.5 \%$ of the surveyed medical professionals define as average their overall satisfaction with their professional activity, $23 \%$ of them - as high, $7.2 \%$ - as low, and $0.4 \%$ express complete overall dissatisfaction with their professional activity. Complex satisfaction is probably only partially based on these factors. Probably other predictors, with a cognitive or an affective component, are involved in its generalized assessment.
The conducted research leads to the following findings:

1. The leading factors, determining satisfaction of the medical professionals: content and organization of work; working conditions and remuneration; mode of work and rest; professional-business relations and overall professional satisfaction have as main manifestation degree the average satisfaction. This is proof of the unsatisfactory social status 
of medical professionals that is, in turn, a very important factor for job satisfaction.

2. Medical professionals place very low levels of complete dissatisfaction. For the determining factor working conditions and remuneration and the manifestation of the criterion amount of remuneration, the medical professionals indicated complete dissatisfaction in $13.2 \%$ and low satisfaction in $35.7 \%$ of the cases. In total, the percentage of these two values is $48.9 \%$, which is very disturbing for the state of emergency medical care. In today's globalizing world, the economic feasibility of the activity is a very important factor for satisfaction, derived from it.

3. The overall satisfaction with the results of the activity is average; therefore, it is necessary to optimize the management and organization of the activity of the medical professionals.

\section{CONCLUSION}

The conducted research allows us to draw the following conclusion:

The briefly outlined conceptual ideas for the formation of the satisfaction of emergency medical professionals reveal that its integrity is determined by multifactorial conditionality.

For the satisfaction of the emergency medical care professionals, it is necessary to provide factors that prevent dissatisfaction with the work and the organization of work, while, at the same time ensure conditions for the normal course of the activity, professional achievements and development.

Well-tested and proven good practices for motivating people at work are the adequate remuneration, the good organization of work, and the number of days off per year.

\section{REFERENCES}

1. Health and well-being at work: a report based on the Fifth Survey on Working Conditions in Europe

(EWCS)

(http://www.eurofound.europa.eu/publication s/htmlfiles/ef1302.htm).

2. Concept for development of the system for emergency medical care in the Republic of $\begin{array}{llll}\text { Bulgaria } 2014 \quad- & 2020\end{array}$ (https://www.mh.government.bg/media/filer_ public/2015/04/15/kontseptsiya-razvitie-naspeshnata-meditsinska-pomosht_26-112014.pdf).
3. Ministry of Health, Rules for amendment and supplement of the Rules for the structure and activity of a center for emergency medical care (promulgated, SG, issue 98 of 1999; amended and supplemented, issue 7 of 2007 , issue 9 of 2009 and 13 of 2011).

4. Mircheva S., M. Milanova, G. Todorova and D. Rangelova I., The shortage of health care specialists - a looming problem for the nation's healthcare. Emergency Medicine, 21(1):91-94,2017.

5. Project BG05M9OP001-3.007-0001 "Improvement of the conditions for treatment of emergencies", funded by the European Social Fund through the Operational Program "Human Resources Development" 20142020.

6. Psychosocial risks and stress at work (https://osha.europa.eu/bg/themes/psychosoci alrisks-and-stress).

7. Rusinova V., Reliability of the Bulgarian adaptation of the occupational stress indicator. In: Sat. The Challenges of Stress, Sofia, Publishing House of the Ministry of Defense "St. G. Victorious", 38-46, 1998.

8. Hristov J., Epidemiology of stress in physicians and teachers in the transition period. Dr. dissertation. Sofia, 209, 2004.

9. Tsenova, B., Stress and mental health at work - perspectives from the point of view of health, politics and business, Health and safety at work, 1:13-25, 2015.

10. Hassard, J. and Cox, T., Work-related stress: Nature and management (https://oshwiki.eu/wiki/Workrelated_stress:_ Nature_and_management).

11. Hupke, M., Psychosocial risks and workers health

(https://oshwiki.eu/wiki/Psychosocial_risks_a nd_workers health).

12. Karasek R., and Theorell T., Healthy work. Stress. Productivity, NY: Basic Books, 1990.

13. Peter Drew, Tippett V., and Devenish S, "Effectiveness of mitigation interventions on occupational violence against emergency service workers," JBI Database of Systematic Reviews and Implementation Reports, 16(5):1081-1086, 2018;.

14. Riggio, R. Introduction to Industrial, Organizational Psychology, 4th edi., Peeearson Education, Inc.,2006.

15. Weibel L, Gabrion I, Aussedat M, Kreutz G., Work-related stress in an emergency medical dispatch center. Annals of Emergency Medicine, 41(4):500-506,2003.

16.https://en.wikipedia.org/wiki/Frederick_Herz berg. 